Canadian

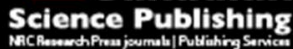

Canadian Geotechnical Journal Revue canadienne de géotechnique

\title{
Incorporating chemical shrinkage volume into Gibson's solution
}

\begin{tabular}{|r|l|}
\hline Journal: & Canadian Geotechnical Journal \\
\hline Manuscript ID & cgj-2017-0028.R1 \\
\hline Manuscript Type: & Note \\
\hline Date Submitted by the Author: & 27-Jul-2017 \\
\hline Complete List of Authors: & $\begin{array}{l}\text { Walske, Megan L.; UWA, School of Civil, Environmental and Mining } \\
\text { Engineering } \\
\text { Doherty, James; University of Western Australia, School of Civil, } \\
\text { Environmental and Mining Engineering }\end{array}$ \\
\hline $\begin{array}{r}\text { Is the invited manuscript for } \\
\text { consideration in a Special } \\
\text { Issue? : }\end{array}$ & $\begin{array}{l}\text { Kemented paste backfill, consolidation, self-desiccation, numerical analysis, } \\
\text { design charts }\end{array}$ \\
\hline Keyword
\end{tabular}

\section{SCHOLARONE \\ Manuscripts}


Incorporating chemical shrinkage volume into Gibson's solution

\author{
Dr. Megan L. Walske ${ }^{1}$ \\ (Email: megan.walske@curtin.edu.au)
}

\title{
Associate Professor James Doherty ${ }^{1}$
}

(Email: james.doherty@uwa.edu.au)

${ }^{1}$ School of Civil, Environmental and Mining Engineering, The University of Western Australia, 35

Stirling Highway, Crawley, Perth, WA 6009, AUSTRALIA

Corresponding Author: Megan Walske (Current address: Department of Civil Engineering, Curtin University, Kent St, Bentley, WA 6102,AUSTRALIA; megan.walske@curtin.edu.au) 
Walske \& Doherty 2017

\section{Abstract}

Rapid filling of low permeability cemented paste backfill (CPB) into underground stopes results in the generation of significant excess pore pressures. These are dissipated through conventional consolidation and shrinkage due to cement hydration. Gibson's solution for excess pore pressures in an accreting sediment can be used to assess the self-weight consolidation of CPB in a stope. In this paper, numerical modelling is used to determine the chemical shrinkage-induced pore pressure response for hydration of $\mathrm{CPB}$ for an accreting material and the results presented in a series of dimensionless design charts. It is shown that superposition can be used to combine Gibson's solution with the newly developed charts for chemical shrinkage-induced pore pressures. This allows a qualitative assessment of potential pore pressure development in a CPB backfilled stope.

Key words: cemented paste backfill; consolidation; self-desiccation; numerical analysis; design charts 
Walske \& Doherty 2017

\section{Introduction}

Cemented paste backfill (CPB) is a common technique used in underground mining to support the excavations created through the mining process and maximum ore recovery. The development of strength and stiffness in cemented paste backfill (CPB), necessary to support these excavations, is related to the effective stress under which the material hydrates. Effective stress in backfill is significantly influenced by the pore pressures within the stope (Helinski et al. 2007), thus it is important to develop an understanding of factors that influence pore pressures during and after stope filling.

A one-dimensional solution to evaluate pore pressures in accreting sedimentation was developed by Gibson (1958). This may be applied to CPB to assess self-weight consolidation excess pore pressures. However, it is unable to account for changes in pore pressure driven by chemical shrinkage which occurs due to cement hydration (Fahey et al. 2010).

Chemical shrinkage occurs in cementing mine backfill due to the cement hydration process whereby the hydration product's density is greater than the average of its constituents (water and cement) (Power, 1935). When the backfill material is saturated, chemically-induced volume changes require pore water movement, resulting in the development of excess pore pressures and subsequent consolidation. If the hydrating mixture has a high permeability, pore fluid can flow under very low hydraulic gradients with no appreciable change in pore pressure or effective stress. However, for low permeability materials, large hydraulic gradients may be required to generate the flow, generating significant negative excess pore pressures and corresponding increases in effective stress (Doherty and Muir Wood 2016; Doherty 2015; Helinski et al. 2010). The typically low permeability values (ranging from $1.7 \times 10^{-5}$ to $1.9 \times 10^{-7} \mathrm{~m} / \mathrm{s}$ ) of $\mathrm{CPB}$ mean that the impact of chemical shrinkage on pore pressure is often significant (Grabinsky and Simms 2006; Helinski et al. 2007, 2011). This is a critical issue in managing mine backfill, as the curing condition impacts backfill strength (Cui and Fall 2017; Ghirian and Fall 2014; Cui and Fall 2015). The cemented 
Walske \& Doherty 2017

strength of mine backfill in turn influences the stress on mine barricades (Li and Aubertin, 2014; Thompson et al. 2012) and the exposure stability (Li 2014).

Muir Wood and Doherty (2014) developed benchmark analytical solutions for coupled shrinkage and consolidation problems, and used these analytical solutions to validate a numerical model using the ABAQUS (2011) finite element software package. This numerical model is used hereto develop and validate a series of design charts that allow chemical shrinkage-induced pore pressures to be superposed with self-weight-induced pore pressures from Gibson's solution, overcoming the limitations of the original solution (Walske 2014). This paper presents solutions for an accreting material with excess pore pressure due to self-weight combined with chemical shrinkage induced pore pressure. The Muir Wood and Doherty (2014) solutions were for a static, weightless material where geometry did not change.

Subsequent work by Muir Wood et al. (2016) has developed a finite difference solution for this problem allowing for changes in permeability and stiffness due to chemical shrinkage to be considered quantitatively. This technical notes however, provides a simplified, qualitative approach to the understanding of excess pore pressure development in CPB backfill through the development of design charts that may be used, as demonstrated in an example of an actual stope backfilling scenario, to assess the impact of hydration on pore pressures, compared with self-weight consolidation alone.

\section{Gibson's Solution}

Gibson's solution (Gibson 1958) was developed for a range of different boundary conditions, assuming a constant permeability $k$, constrained modulus $E_{0}$ and coefficient of consolation $c_{v}$, where

$$
c_{v}=\frac{E_{0} k}{\gamma_{w}}
$$

and $\gamma_{\mathrm{w}}$ is the unit weight of the pore fluid. 
Walske \& Doherty 2017

Fahey et al. (2010) identified the drained base and constant filling rate scenario from Gibson's solution to be most relevant to the deposition of CPB in an excavated stope (Figure 1).

The CPB fill height $(H(t))$ is determined based on a constant filling rate $(m)$ and the time since fill commencement $(t)$ such that

$$
H(t)=m t
$$

The base of the stope and top fill surface are assumed to be fully drained such that pore pressure $(u)$ is zero $(u=0)$ at $z=0$ and $z=H(t)$, where $z$ is a vertical coordinate measuring the height above the base of the stope. These boundary conditions can reasonably approximate the boundary conditions of a stope with a permeable base of a drainage system installed in the barricade wall.

Gibson's solution is presented in terms of a dimensionless time factor $T$,

$$
T=\frac{m^{2} t}{c_{v}}=\frac{m H(t)}{c_{v}}
$$

and plotted in dimensionless form in Figure 2, where $\gamma$ is the unit weight of the fill.

Self-weight consolidation was also modelled numerically using ABAQUS, by creating a onedimensional model composed of separate, initially deactivated layers. A staged analysis was conducted by activating layers from the bottom upward at a rate corresponding to a given fill rate (m) (Figure 3). Self-weight loading was applied to each layer, with zero pore pressure boundary conditions prescribed to the bottom of the model and to the top of active upper layer (i.e. $u=0$ at $z$ $=0$ and $z=H(t))$. Results from the analysis for a model filled in 20 layers demonstrate an excellent match to Gibson's solution (Figure 2). The significant limitation of Gibson's solution is the inability to account for chemical shrinkage; this must be considered separately. 
Walske \& Doherty 2017

\section{Chemical Shrinkage}

The shrinkage associated with hydration is proportional to the degree of hydration (Power 1935; Parrott et al. 1990; Bentz et al. 2008), and assuming that the degree is inversely proportional to the rate of hydration, a maturity function (Muir Wood and Doherty 2014) can be used to define the volume strain induced by the chemical shrinkage $\left(\varepsilon_{s h}\right)$ as a function of time.

$$
\varepsilon_{s h}\left(t^{\prime}\right)=\varepsilon_{s h f}\left(1-\exp \left(-\kappa_{h} t^{\prime}\right)\right)
$$

where $\varepsilon_{s h f}$ is the chemical volume strain after full hydration, $\kappa_{h}$ is a parameter controlling the rate of hydration, with units of $t^{-1}$, and $t^{\prime}$ is the time since commencement of hydration. The parameter $\kappa_{h}$ could be determined from a hydration cell test as demonstrated by Doherty and Muir Wood (2016). Chemical shrinkage is considered to be the primary cause of self-desiccation in CPB and is the focus of this paper. Autogenous shrinkage (a subset of chemical shrinkage) only occurs where no free water exists within the system (Tazawa et al. 1995; Sant et al. 2006); this is not the case with $\mathrm{CPB}$ due to the high $\mathrm{w} / \mathrm{c}$ ratios typical of $\mathrm{CPB}$.

Muir Wood and Doherty (2014) compare chemical shrinkage strain data for various mortar mixes, provided by Bentz (2005), with Equation 4 and demonstrate a reasonable match. This equation is plotted in dimensionless form in Figure 4.

Muir Wood and Doherty (2014) showed that an incremental volume strain $\delta \varepsilon_{s h}\left(t^{\prime}\right)$ can be generated by a change in pore pressure $\left(\delta u\left(t^{\prime}\right)\right)$ given by

$$
\delta u\left(t^{\prime}\right)=E^{*} \delta \varepsilon_{s h}\left(t^{\prime}\right)
$$

where

$$
E^{*}=\frac{1}{1 / E_{0}+n / K_{w}}
$$


Walske \& Doherty 2017

and where $n$ is the porosity of the material, which may change as a function of time due to porosity reduction with cement gel growth and changes in effective stress. $K_{w}$ is the bulk stiffness of the pore fluid, assumed to be water (2,000 MPa).

If the hydration of the backfill commences at the time of deposition, (in reality this may not be the case, but is assumed here for simplicity), then the hydration time $\left(t^{\prime}\right)$ at a particular location through the height $(z)$ can be related to the time since filling commences $(t)$ and the fill rate $(m)$.

$$
t^{\prime}=t-\frac{z}{m}
$$

Muir Wood and Doherty (2014) showed for a one-dimensional problem with shrinkage strain as in Equation 5, that the pore pressure is governed by the dimensionless parameter

$$
\kappa^{*}=\frac{\kappa_{h} H^{2}}{c_{v}}
$$

where $H$ is the length of the drainage path. Combining Equation 3 and 8, it can be shown that

$$
\kappa^{*}=\kappa_{h} t T
$$

Therefore the fill time $(t)$ and hydration rate $\left(\kappa_{h}\right)$ provide a link between the term controlling the self-weight consolidation $(T)$ and the term controlling the pore pressure due to chemical shrinkage $\left(\kappa^{*}\right)$. The hydration profile with depth is also controlled by the actual fill time $(t)$ and the rate of hydration $\left(\kappa_{h}\right)$, when $t^{\prime}$ is expressed by Equation 7. For example, it can be shown that for $\kappa_{h} t=0.22$, $0.51,0.92,1.62,2.3$ and 4.61 , the material has achieved $20,40,60,80,90$ or 99 percent hydration respectively at $z=0$; while for $\kappa_{h} t=5.76,7.67,11.51,23.03,46.1$ and 92.1 the material achieves 99 percent hydration at $z / H=0.2,0.4,0.6,0.8,0.9$ and 0.99 , respectively (Figure 5).

In the absence of an analytical solution, ABAQUS (2011) was employed to numerically model the chemical shrinkage-induced pore pressures in a material increasing with thickness over time. Like the self-weight analysis, the chemical shrinkage model comprised 20 layers, which were added over 
Walske \& Doherty 2017

a time period corresponding to a given fill rate (see Figure 3). Zero pore pressure boundary conditions were prescribed at the base of the model and at the current upper surface. The chemical shrinkage function in Equation 4 was applied (as described by Muir Wood and Doherty 2014), where $t^{\prime}$ varied through the height of the model according to Equation 7. The fill was assumed to be weightless to allow independent observation of shrinkage effects on the pore pressures.

The results of this analysis are presented in a series of dimensionless charts (Figure 6 and 7) similar to Gibson's solution, allowing determination of pore pressure $u$ at varying heights within the deposited fill, at different dimensionless fill times $(T)$ within the hydration process $\left(\kappa_{h} t=0.22,0.51\right.$, 0.92, 1.61, 2.30, 4.61, 5.76, 7.67, 11.51, 23.03, 46.1, 92.1). Repeated ABAQUS simulations generated identical results regardless of the individual parameters provided the parameter groups were constant.

These charts provide insight into the influence fill time $(t)$ and hydration rate $\left(\kappa_{h}\right)$ have on shrinkage-induced pore pressures. The shapes of the isochrones vary as a function of $\kappa_{h} t$ because hydration profiles also vary with $\kappa_{h} t$ (Figure 5). For low values of $\kappa_{h} t$ (slow rate of hydration compared with fill time), the magnitude of shrinkage-induced pore pressure is relatively low. It can be seen that the shrinkage-induced pore pressure increases up to $\kappa_{h} t=11.5$ and then reduces with a further increase in $\kappa_{h} t$. This is evident in Figure 8, where the normalised pore pressure $\left(u / E^{*} \varepsilon_{s h f}\right)$ at $z / H=0.5$, for various $T$ values, is plotted against the normalised fill time $\left(\kappa_{h} t\right)$.

The optimum fill times required to achieve the maximum shrinkage-induced pore pressure at $z / H=$ 0.5 , range from $2.3<\kappa_{h} t<11.5$, beyond which the magnitude of shrinkage-induced pore pressure reduces. Note, $\kappa_{h} t^{\prime}=5$ indicates "practical" completion of hydration (Figure 4). This timeframe is significantly greater than typical backfilling times (usually 1-4 days), such that filling times may be unable to capitalise on peak negative pore pressures occurring due to chemical shrinkage. 
Walske \& Doherty 2017

\section{Superposition of pore pressure profiles}

The total pore pressure response due to both self-weight consolidation and chemical shrinkage may be determined via superposition of Gibson's solution (Figure 2), with the shrinkage-induced pore pressure response (Figure 6 or 7). This was verified by conducting ABAQUS simulations that included both self-weight loading and chemical shrinkage. Simulations were then conducted that included (A) only self-weight loading and (B) only chemical shrinkage. It was found that the sum of A and B was identical to the initial simulation that included both self-weight loading and chemical shrinkage. This was confirmed for a number of parameter sets, and an example of this for a particular parameter set is given in Figure 9.

\section{Example Application}

The charts (Figure 2 and Figure 6 and 7) were applied to a real stope filling scenario with parameters derived from actual stope filling data, the relevant details of which are provided here (Helinski et al. 2011). A $40 \mathrm{~m}$ stope is filled with CPB at a rate of $7.2 \mathrm{~m} / \mathrm{day}$, such that $H=40 \mathrm{~m}, m$ $=0.254 \mathrm{~m} /$ hour (averaged to include a 24 hour rest period), $c_{v}=0.25 \mathrm{~m}^{2} /$ hour and $t=157.3$ hours,

giving $T=40.67$ (Equation 3). The hydration process is characterised by $\kappa_{h}=8.3 \times 10^{-3}$ hours $^{-1}, \varepsilon_{s h f}=$ 0.0026 and $E^{*}=65,000 \mathrm{kPa}$, giving $\kappa_{h} t=1.3$.

The individual charts do not show isochrones for $T=40.67$, nor $\kappa_{h} t=1.3$. However, to highlight the practical application of these charts in the absence of a fully-coupled ABAQUS analysis, the upper and lower bound of pore pressure ranges are determined through superposition of the self-weight consolidation isochrones for $T=32$ and shrinkage isochrones for $T=32$ and $\kappa_{h} t=0.92$ and 1.61 respectively, as shown in Figure 10. 
Walske \& Doherty 2017

\section{Conclusion}

A series of numerically-generated, dimensionless charts for shrinkage-induced pore pressures within a weightless material in a one-dimensional column increasing with thickness over time have been presented. Curves from these charts have been shown to successfully superpose with curves from Gibson's consolidation solution. The charts provide a convenient method for estimating excess pore pressures in an accreting material that includes the effects of chemical shrinkage and self-weight loading. A key outcome is the ability to quickly assess the relative importance of chemical shrinkage on the pore pressure within a stope. This was achieved through the identification of a link between the standard term controlling self-weight consolidation, $T$, and the term controlling pore pressure response to hydration, $\kappa^{*}$ and a suitable form of normalised shrinkage-induced pore pressure, $u / E^{*} \varepsilon_{s h f}$.

While these charts do not necessarily provide a quantitative assessment of the pore pressures present within a stope during filling, they are able to provide an indicative, qualitative assessment of the pore pressure behaviour due to self-weight consolidation and chemical shrinkage, both independently and in combination.

\section{Acknowledgements}

The authors acknowledge funding provided by an ARC Linkage Grant (LP100200173) in collaboration with Barrick (Australia Pacific) Limited and Panoramic Resources Limited 
Walske \& Doherty 2017

\section{References}

ABAQUS analysis users' manual; version 6.11. 2011. Dassualt Systèmes Simula Corp., Providence, R.I.

Bentz, D.P., Sant, G. and Weiss, J. 2008. Early-age properties of cement-based materials. I : Influence of cement fineness. Journal of Materials in Civil Engineering 20(7): 502-509.

Bentz D. P. 2005. Capitalizing on self-desiccation for autogenous distribution of chemical admixtures. In Proceedings of 4th International Seminar on Self-desiccation and its importance in concrete technology (B. Persson, D. Bentz, and L.-O. Nilsson (eds)), Lund University, Sweden, pp. 189-196.

Cui, L. and Fall, M. 2015. A coupled thermo-hydro-mechanical-chemical model for underground cemented tailings backfill. Tunnelling and Underground Space Technology. 50: 396-414.

Cui, L. and Fall, M. 2017. Multiphysics modeling of arching effects in fill mass. Computers and Geotechnics. 83:114-131.

Doherty, J.P 2015. A numerical study into factors affecting stress and pore pressure in free draining mine stopes. Computer and Geotechnics 63: 331-341 ( DOI: 10.1016/j.compgeo.2014.10.001)

Doherty, J.P., and Muir Wood, D. 2016. Back analysis of Kanowna Belle stope filling case history. Computer and Geotechnics 76: 201-21.

Fahey, M., Helinski, M., and Fourie, A.B. 2009. Some aspects of the mechanics of arching in backfilled stopes. Canadian Geotechnical Journal 46: 1322-1336.

Fahey, M., Helinski, M., and Fourie, A.B. 2010. Consolidation in accreting sediments: Gibson's solution applied to backfilling of mine stopes. Géotechnique 60(11): 877-882.

Geiker, M., and Knudsen, T. 1982. Chemical Shrinkage of Portland Cement Pastes. Cement and Concrete Research 12: 603-610. 
Walske \& Doherty 2017

Ghirian, A., and Fall, M. 2014. Coupled thermo-hydro-mechanical-chemical behaviour of cemented paste backfill in column experiments: Part II: Mechanical, chemical and microstructural processes and characteristics. Engineering Geology. 170:11-23.

Gibson, R.E. 1958. The progress of consolidation in a clay layer increasing in thickness with time. Géotechnique, 8(4), 171-182.

Grabinsky, M.W., and Simms, P. 2006. Self-Desiccation of Cemented Paste Backfill and Implications for Mine Design. In R. J. Jewell, S. Lawson, and P. Newman (Eds). Proceedings of the 9th International Seminar on Paste and Thickened Tailings (pp. 323-332). Limerick, Ireland: Australian Centre for Geomechanics,

Helinski, M., Fourie, A.B., Fahey, M., and Ismail, M. 2007. Assessment of the self-desiccation process in cemented mine backfills. Canadian Geotechnical Journal 44: 1148-1156.

Helinski, M., Fahey, M., and Fourie, A.B. 2011. Behavior of Cemented Paste Backfill in Two Mine Stopes: Measurements and Modeling. Journal of Geotechnical and Geoenvironmental Engineering 137(2): $171-182$.

Li, L. 2014. Analytical solution for determining the required strength of a side-exposed mine backfill containing a plug. Canadian Geotechnical Journal 51(5): 508-519

Li, L., Aubertin, M. 2009. Horizontal pressure on barricades for backfilled stopes. Part I: Fully drained conditions Canadian Geotechnical Journal, 46(1): 37-46

Muir Wood, D., and Doherty, J. 2014. Coupled chemical shrinkage and consolidation: some benchmark solutions. Transp Porous Med. DOI 10.1007/s11242-014-0372-x).

Muir Wood, D., Doherty, J.P. and Walske, M.L. (2016) Deposition and self-weight consolidation of a shrinking fill. Géotechnique Letters 6: 72-76, http://dx.doi.org/10.1680/jgele.15.00142 
Walske \& Doherty 2017

Parrott, L., Geiker, M., Gutteridge, W.A., and Killoh, D. 1990. Monitoring Portland cement hydration: comparison of methods. Cement and Concrete Research 20: 919-926.

Powers, T. 1935. Absorption of Water by Portland Cement Paste during the Hardening Process. Industrial \& Engineering Chemistry 27(7): 790-794.

Sant, G., Lura, P., and Weiss, J. 2006. Measurement of Volume Change in Cementitious Materials at Early Ages: Review of Testing Protocols and Interpretation of Results. Journal of the Transportation Research Boards, 1979, 21-29

Tazawa, E., Miyazawa, S., and Kasai, T. 1995. Chemical shrinkage and autogenous shrinkage of hydrating cement paste. Cement and Concrete Research, 25(2), 288-292

Thompson, B., Bawden,W., and Grabinsky, M. 2012. In situ measurements of cemented paste backfill at the Cayeli mine. Canadian Geotechnical Journal, 49(7): 755-772

Walske, M.L. 2014. An Experimental Study of Cementing Paste Backfill (Doctoral dissertation, PhD thesis. School of Civil, Environmental and Mining Engineering, University of Western Australia, Perth, Australia). 
Walske \& Doherty 2017

\section{Figures}

Figure 1 Boundary conditions of CPB deposition in a stope.

Figure 2 Isochrones of pore pressure from Gibson's solution.

Figure 3 ABAQUS staged analysis for modelling self-weight consolidation.

Figure 4 Normalised chemical shrinkage against dimensionless time.

Figure 5 Isochrones of shrinkage with depth for various dimensionless fill times $\left(\kappa_{h} t\right)$.

Figure 6 Isochrones of normalised pore pressure due to chemical shrinkage at various dimensionless fill times.

Figure 7 Isochrones of normalised pore pressure due to chemical shrinkage at various dimensionless fill times.

Figure 8 Isochrones of normalised pore pressure due to chemical shrinkage at various dimensionless fill times.

Figure 9 ABAQUS analysis of pore pressure due to self-weight consolidation (self-weight only $(A)$ ), chemical shrinkage (shrinkage only $(B)$ ), coupled self-weight and shrinkage (Both $A \& B$ ) and superposition of self-weight and shrinkage $(A+B)$.

Figure 10 Analytical analysis of pore pressure due to self-weight consolidation (self-weight), chemical shrinkage (shrinkage) and superposition of self-weight and shrinkage (superposition) for $T=32$ and $\kappa_{h} t=0.92$ and 1.61 and $E^{*} \varepsilon_{s h f}=169$. 


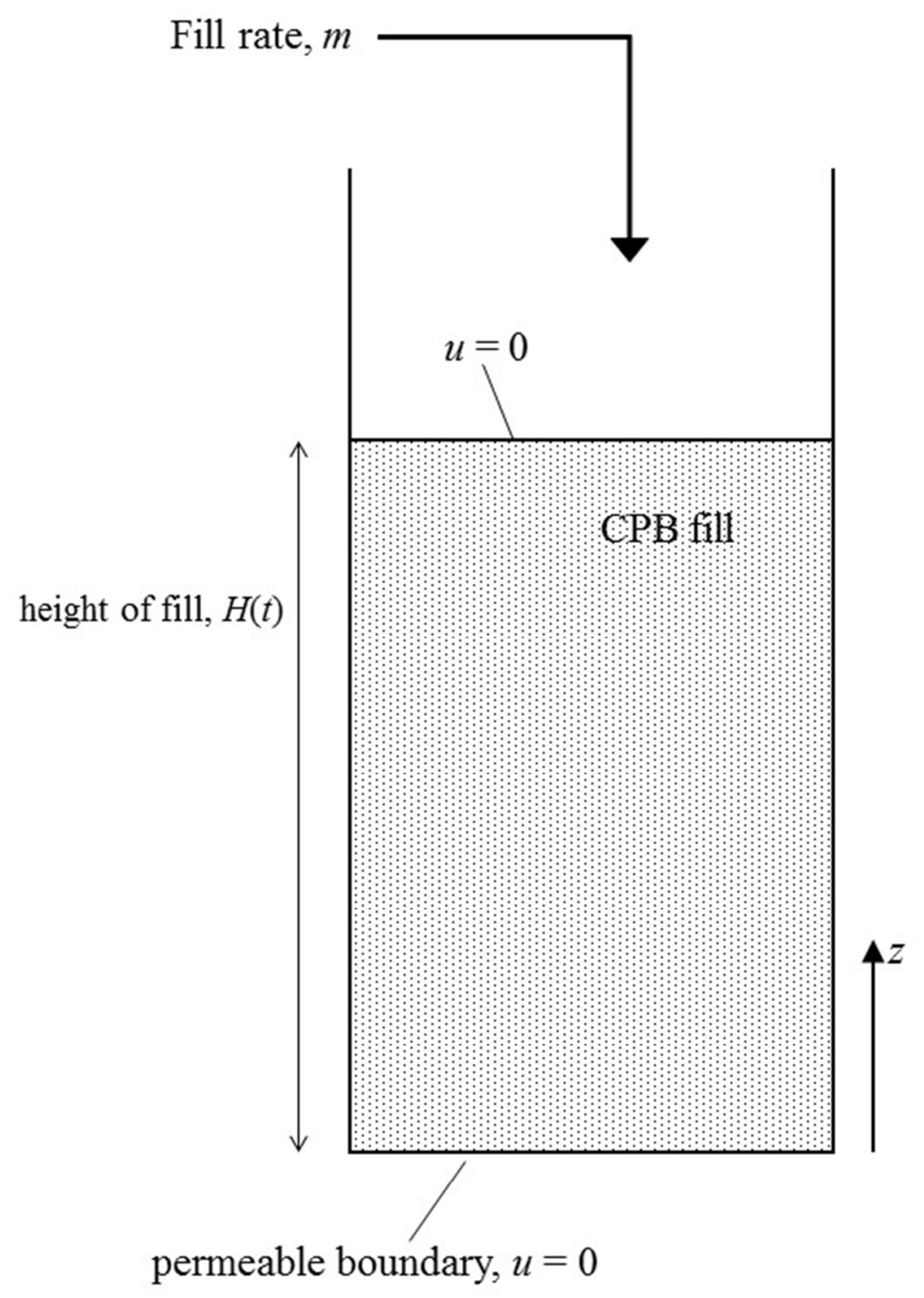

Figure 1 Boundary conditions of CPB deposition in a stope. $143 \times 206 \mathrm{~mm}(96 \times 96$ DPI $)$ 


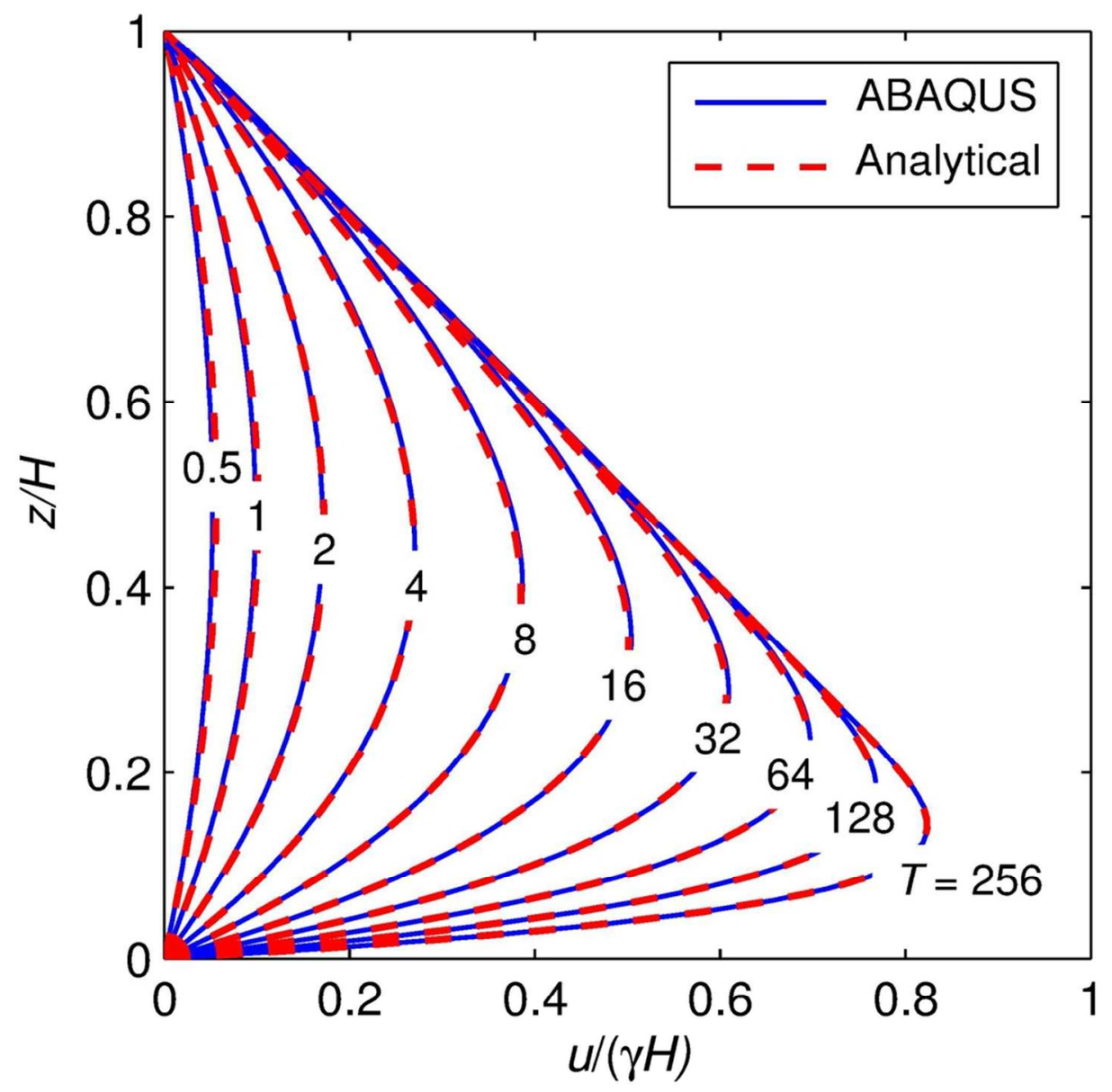

Figure 2 Isochrones of pore pressure from Gibson's solution.

$95 \times 96 \mathrm{~mm}(300 \times 300 \mathrm{DPI})$ 


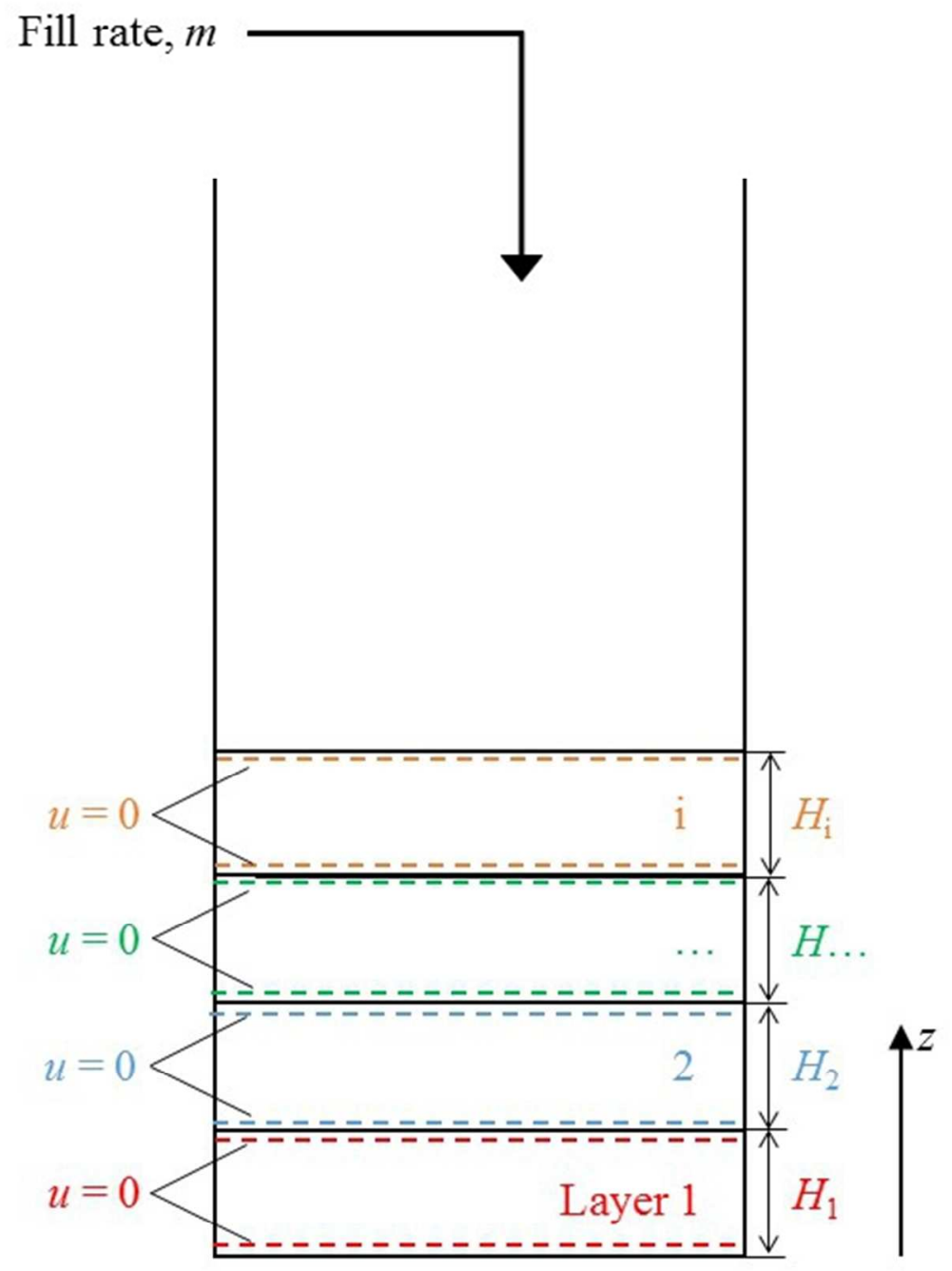

Figure 3 ABAQUS staged analysis for modelling self-weight consolidation. $143 \times 206 \mathrm{~mm}(96 \times 96$ DPI) 


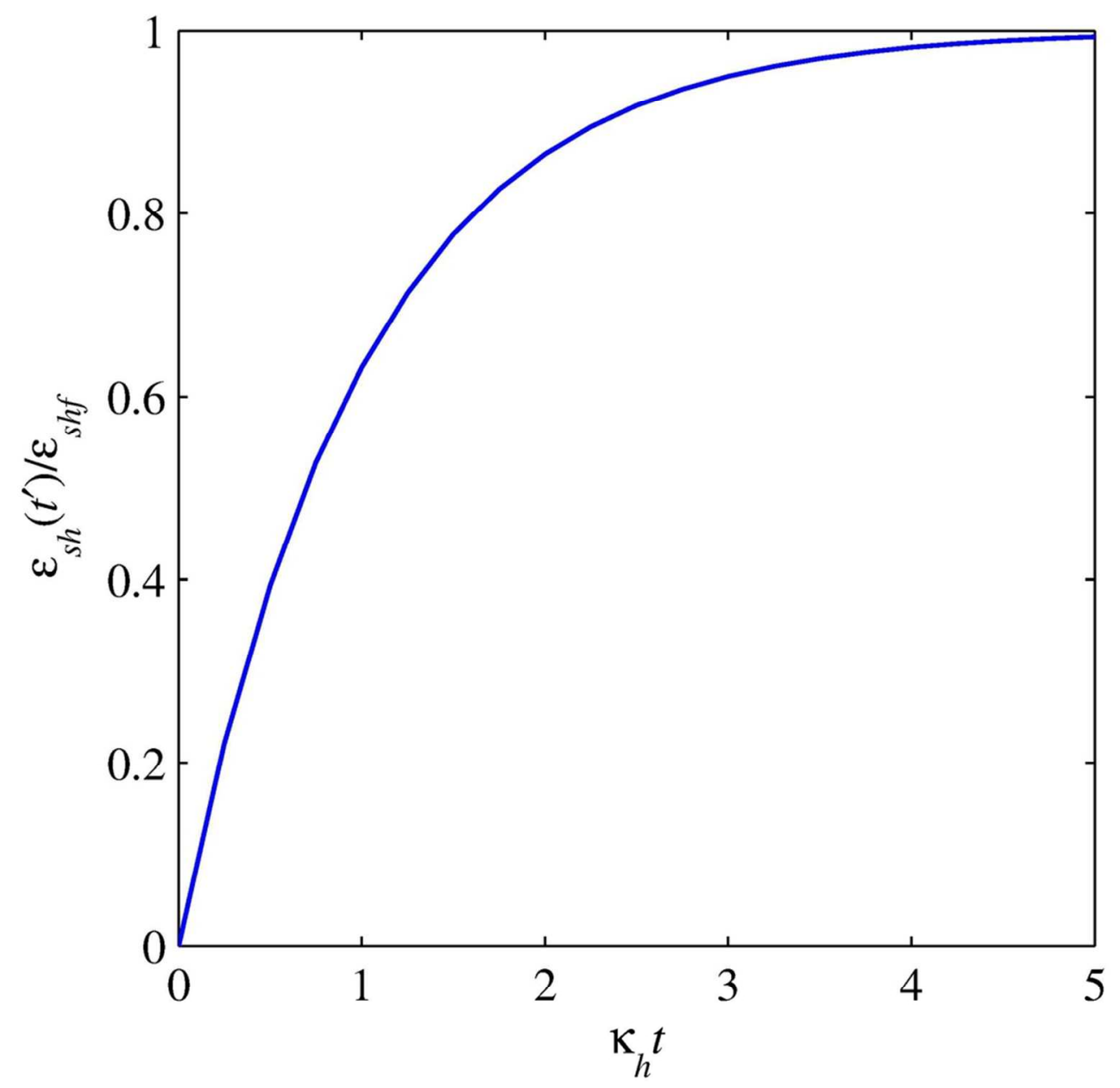

Figure 4 Normalised chemical shrinkage against dimensionless time.

$90 \times 89 \mathrm{~mm}(300 \times 300$ DPI $)$ 


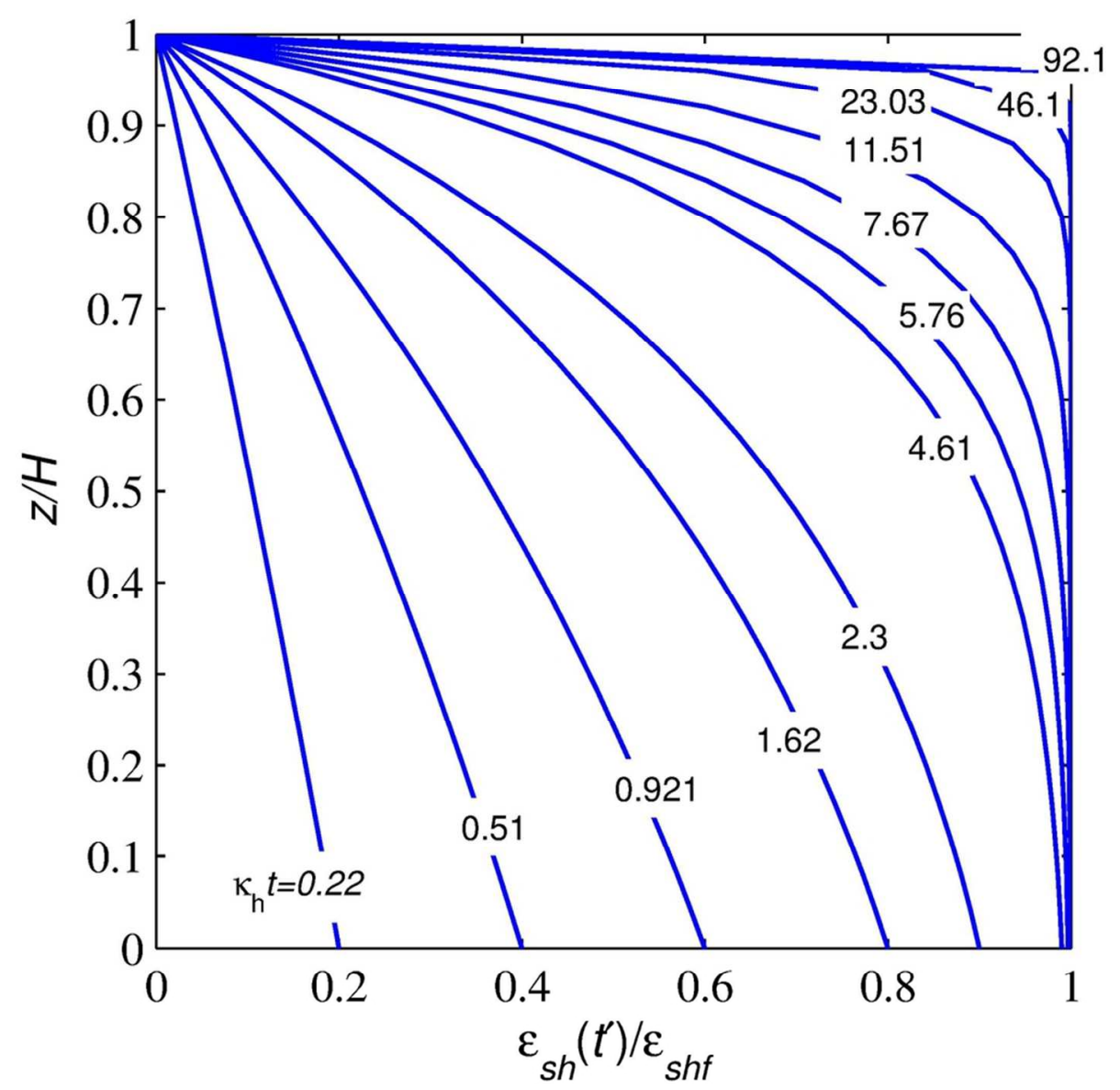

Figure 5 Isochrones of shrinkage with depth for various dimensionless fill times $\left(\kappa_{h} t\right)$. $93 \times 88 \mathrm{~mm}(300 \times 300 \mathrm{DPI})$ 
a) $\kappa_{h} t=0.22$

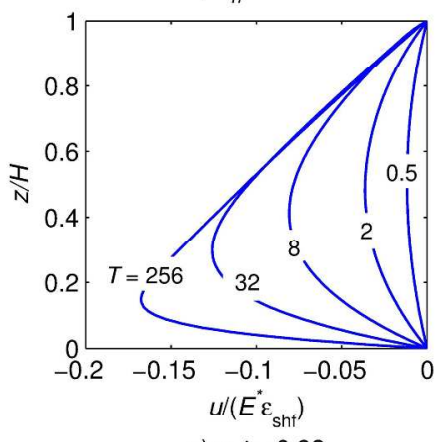

c) $\kappa_{h} t=0.92$

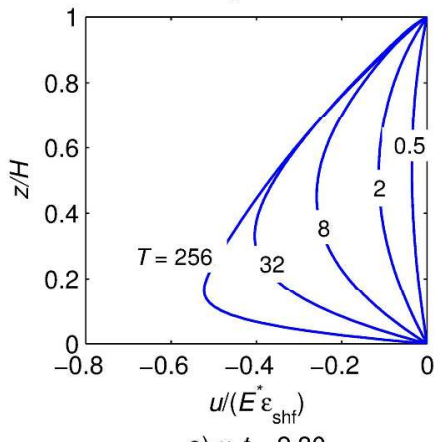

e) $\kappa_{h} t=2.30$

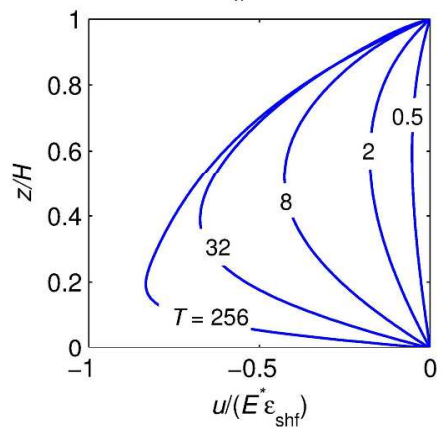

b) $\kappa_{h} t=0.51$

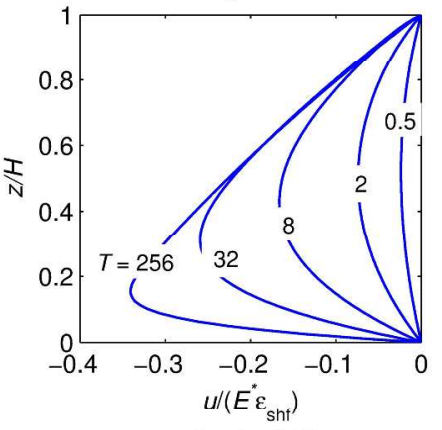

d) $\kappa_{h} t=1.61$

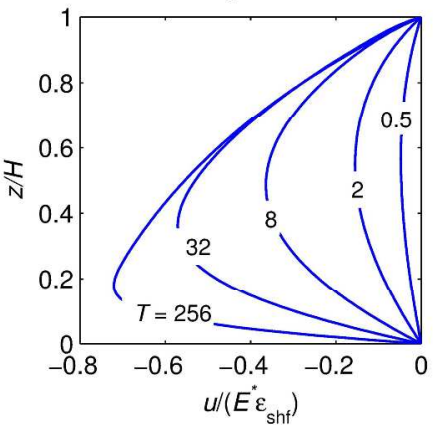

f) $\kappa_{h} t=4.61$

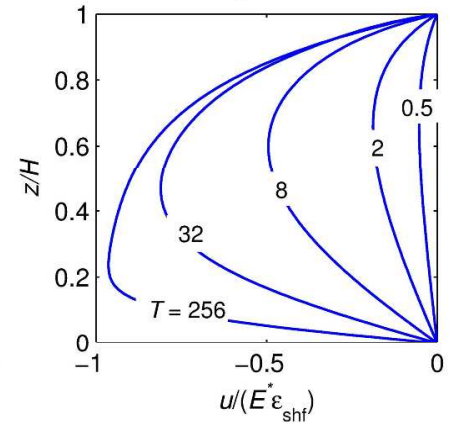

Figure 6 Isochrones of normalised pore pressure due to chemical shrinkage at various dimensionless fill times.

$240 \times 368 \mathrm{~mm}(300 \times 300 \mathrm{DPI})$ 
a) $\kappa_{h} t=5.76$

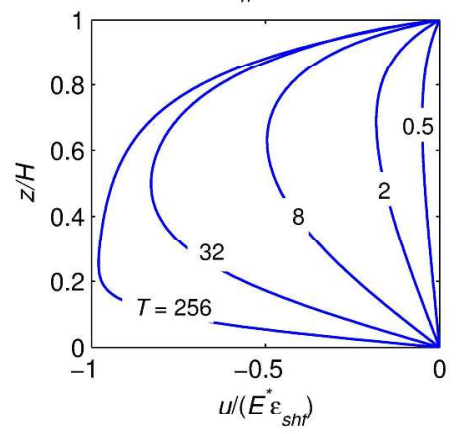

c) $\kappa_{t} t=11.51$

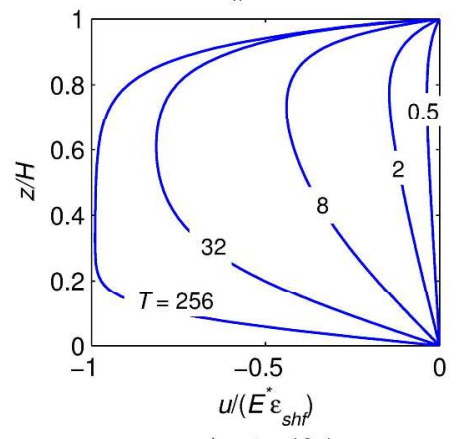

e) $\kappa_{h} t=46.1$

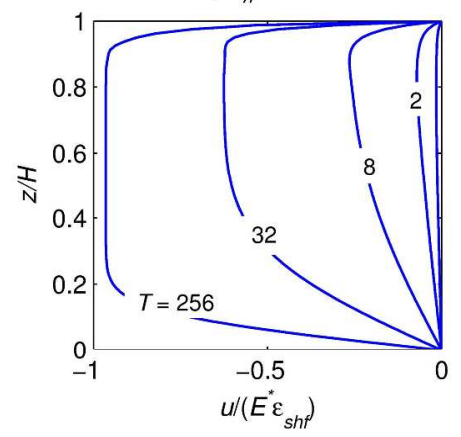

b) $\kappa_{h} t=7.67$

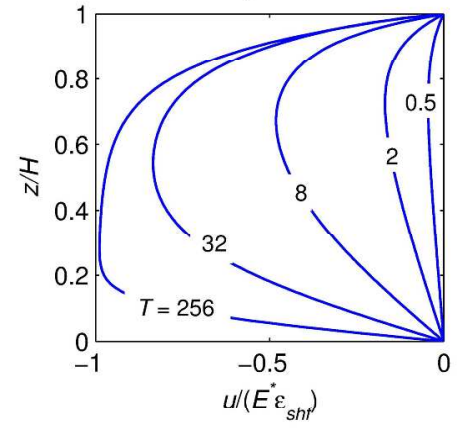

d) $\kappa_{h} t=23.03$

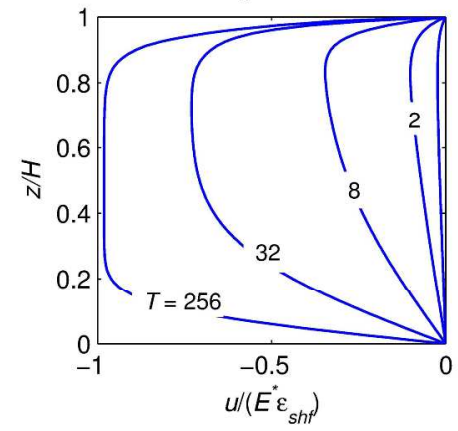

f) $\kappa_{h} t=92$

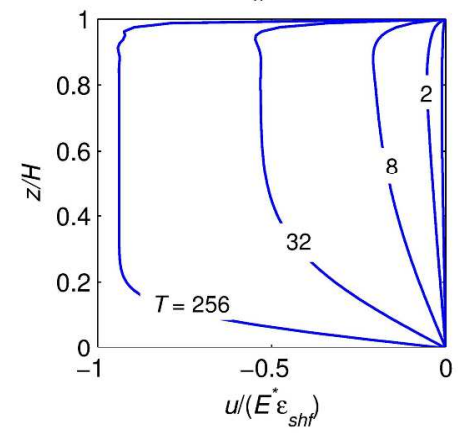

Figure 7 Isochrones of normalised pore pressure due to chemical shrinkage at various dimensionless fill times.

$240 \times 360 \mathrm{~mm}(300 \times 300 \mathrm{DPI})$ 


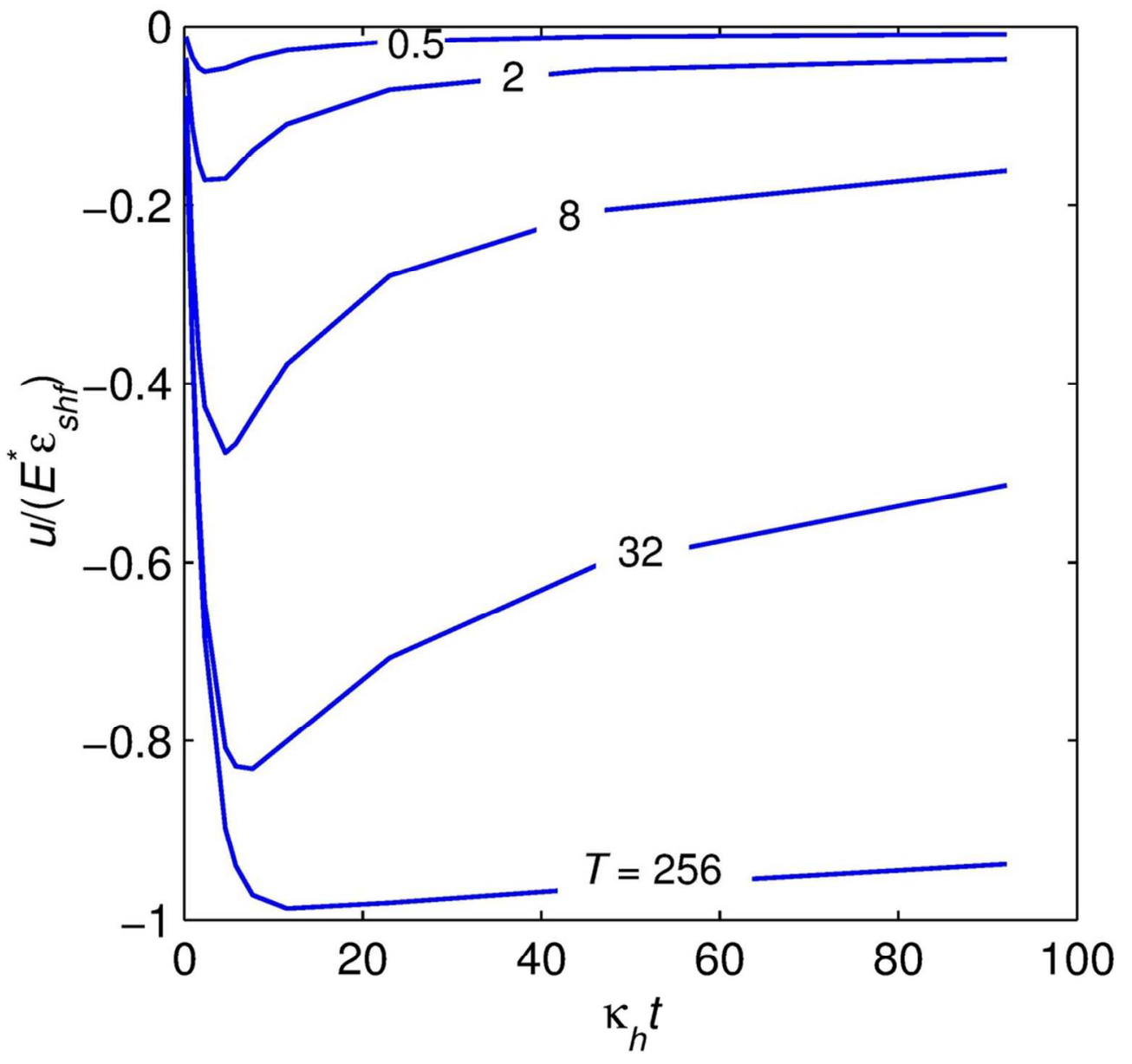

Figure 8 Isochrones of normalised pore pressure due to chemical shrinkage at various dimensionless fill times.

$95 \times 96 \mathrm{~mm}(300 \times 300$ DPI $)$ 


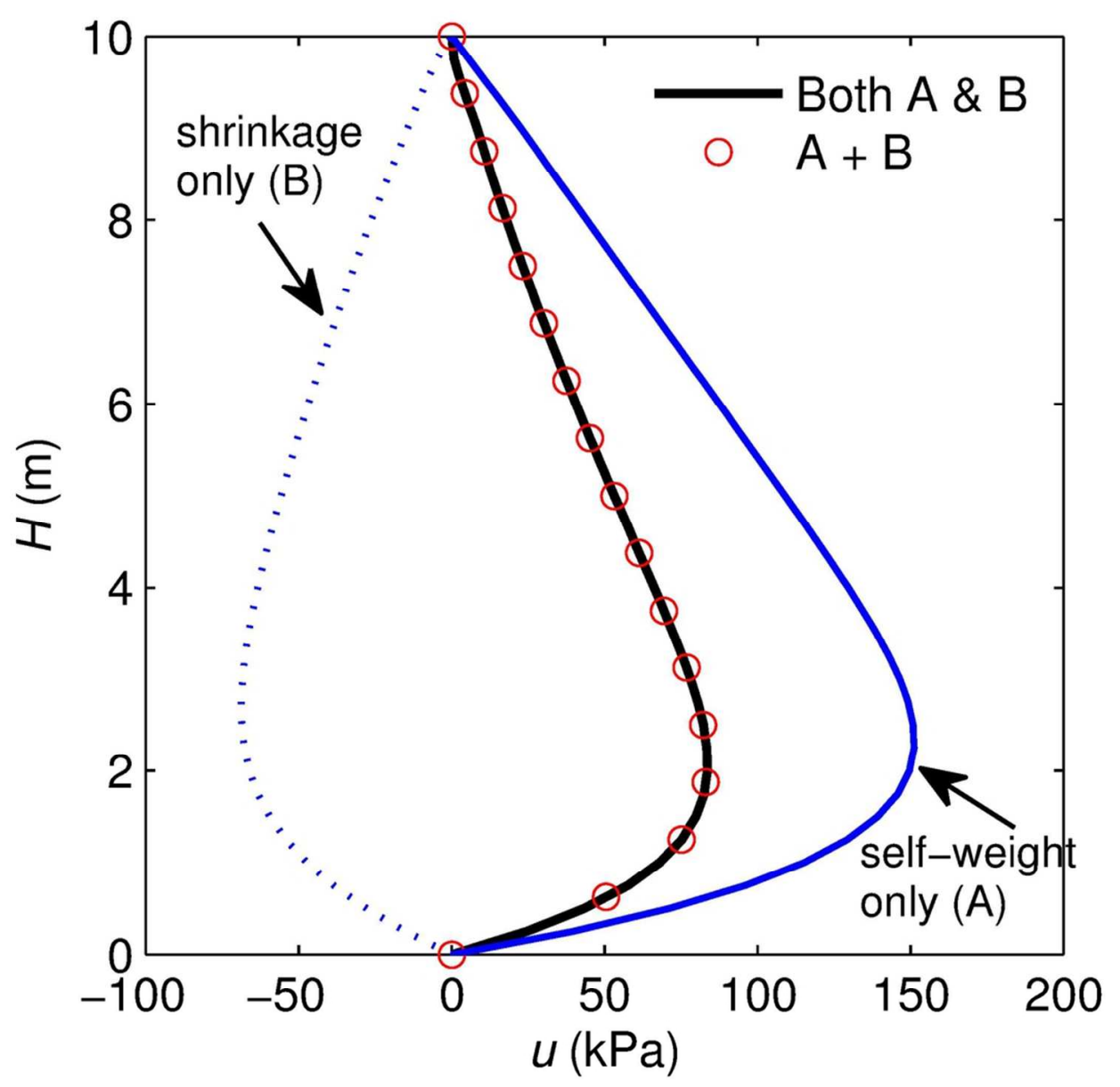

Figure 9 ABAQUS analysis of pore pressure due to self-weight consolidation (self-weight only $(A)$ ), chemical shrinkage (shrinkage only $(B)$ ), coupled self-weight and shrinkage (Both $A \& B$ ) and superposition of selfweight and shrinkage $(A+B)$.

$95 \times 95 \mathrm{~mm}(300 \times 300 \mathrm{DPI})$ 


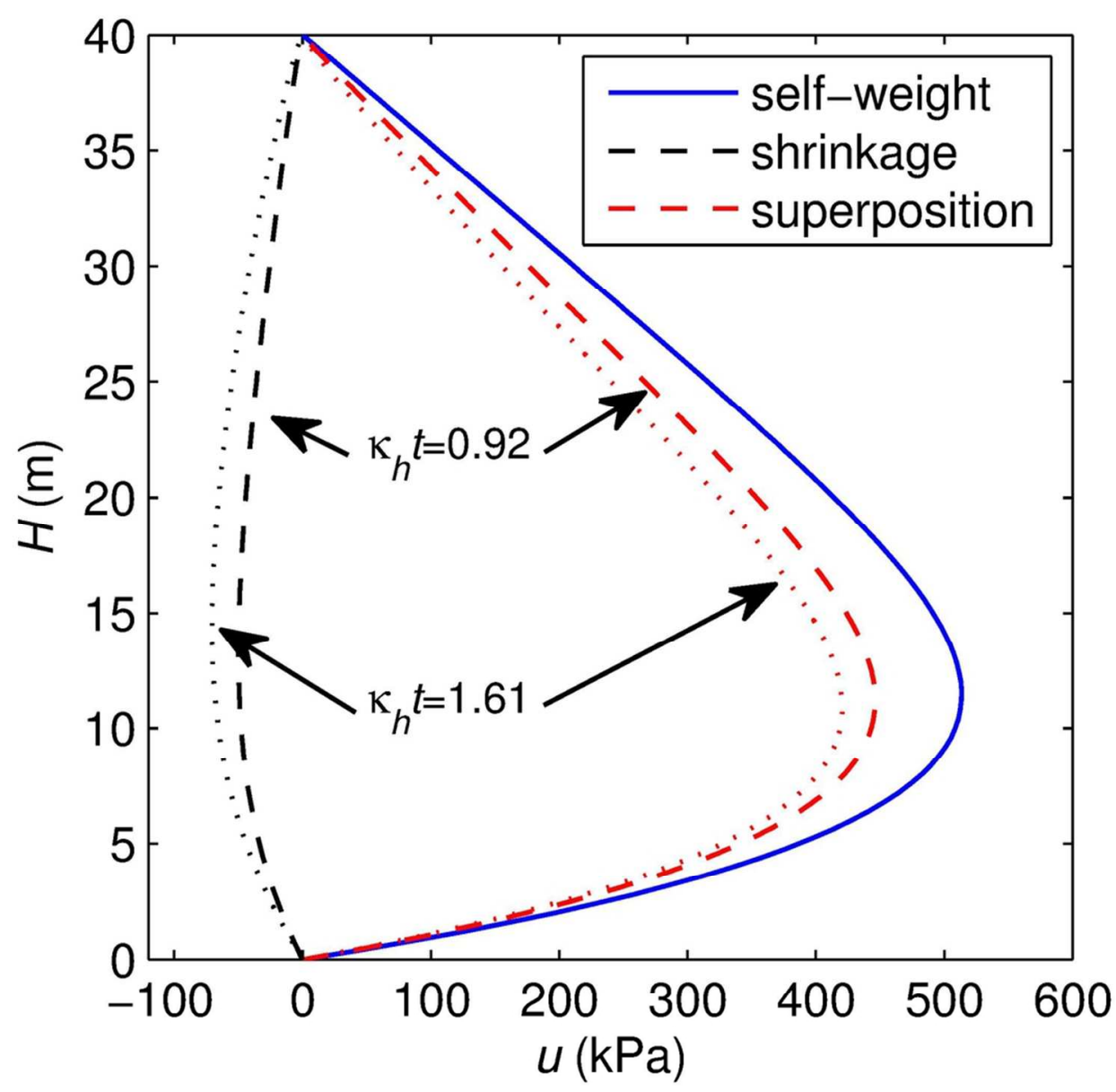

Figure 10 Analytical analysis of pore pressure due to self-weight consolidation (self-weight), chemical shrinkage (shrinkage) and superposition of self-weight and shrinkage (superposition) for $T=32$ and $k_{h} t=$ 0.92 and 1.61 and $E^{*} \varepsilon_{\text {sh } f}=169$.

$95 \times 95 \mathrm{~mm}(300 \times 300 \mathrm{DPI})$ 